\title{
Sob a Espada de Dâmocles: a Prática de Psicólogas em Oncologia Pediátrica em Recife-Pe
}

Under The Sword Of Damocles: The Practice Of Psychologists In Pediatric Oncology In Recife-Pe

Bajo La Espada De Damocles: La Práctica De Psicólogos En Oncología Pediátrica En Recife-Pe

Sílvia Raquel Santos de Morais \& Ângela Nobre de Andrade

Universidade Federal do Espírito Santo

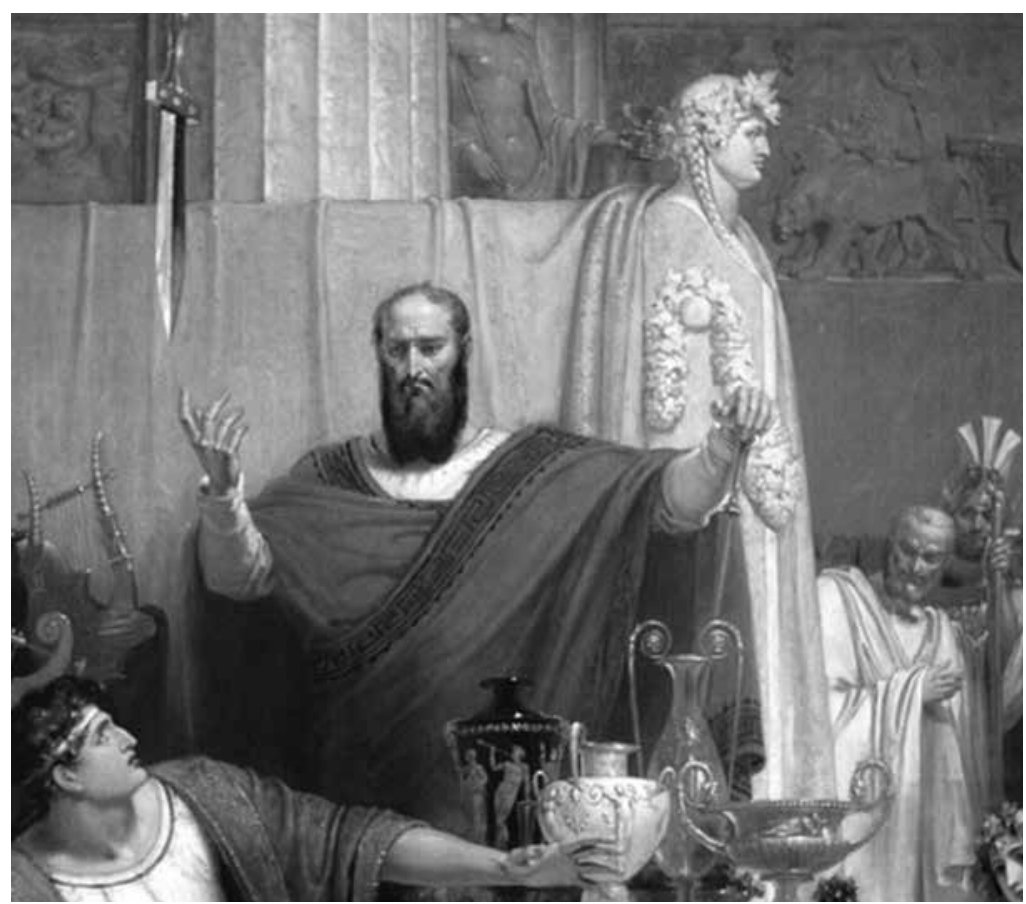


Resumo: A prática de psicólogos em oncologia pediátrica envolve demandas ligadas ao processo de adoecimento e suas implicações psicossociais, e, não raro, iminência de morte e/ou até chances de cura. Assim, tal pesquisa objetivou compreender a prática desses profissionais no Município de RecifePE. A metodologia foi qualitativa de inspiração fenomenológica, ancorada na ontologia heideggeriana. Os instrumentos utilizados foram: entrevistas, grupo focal e diálogos com nove participantes, além das anotações de campo. As narrativas foram transcritas na íntegra, literalizadas (Schmidt, 1990) e interpretadas mediante a analítica do sentido (Critelli, 2007). A prática caracterizou-se pela coexistência dos seguintes aspectos: longo período de convivência de pacientes e familiares, envolvimento afetivo e proximidade entre profissionais de saúde, familiares e crianças, além da intensidade no que diz respeito aos vínculos estabelecidos. Tais dimensões repercutem nos modos-de-ser e de estar-no-mundo das participantes, fazendo a prática transitar por entre as dimensões ôntica e ontológica do cuidado. Com o tempo, a prática tende a ancorar-se nas experiências de coexistência. Exercício ético de acolhimento à alteridade, impossibilidade de controle dos acontecimentos, além da iminência de morte, perpassam tal prática, levando os profissionais a romper ações isoladas, a redimensionar o saber-fazer e a reinventar modos interventivos por meio da experimentação cotidiana.

Palavras-chave: Cuidado. Psico-oncologia pediátrica. Prática (Psicologia). Morte.

Abstract: The practice of psychologists in pediatric oncology is recent and involves claims related to the disease process and its psychosocial implications, and not infrequently, the imminence of death or even chances of cure. Thus, this research aimed at understanding the practice of professionals in Recife-PE. The methodology was the qualitative phenomenological inspiration. The instruments used were: interviews, focus groups and conversations with nine participants in addition to the field notes. The narratives were transcribed verbatim, literalized (Schmidt, 1990) and interpreted by the analytic sense (Critelli, 2007). The practice was characterized by the coexistence of the following: long period of familiarity with patients and families, emotional involvement and closeness between them, and the intensity with respect to the links forged. These dimensions resonate in the ways-of-being and being-in-the-world of the participants, making the practice move through the ontic and ontological dimensions of care. Over time, the practice tends to be anchored in the experiences of co-existence. This practice includes an ethical exercise to host differences, inability to control events, and also the imminence of death that pervades the practice, casting professionals to break away from individual stocks, re-size the know-how and re-invent interventional modes by daily trial. Keywords: Care. Pediatric psycho-oncology. Practice (Psychology). Death.

Resumen: La práctica de psicólogos en oncología pediátrica involucra demandas relacionadas al proceso de enfermedad y sus implicaciones psicosociales, y, no raro, inminencia de muerte y/o hasta chances de cura. Así, tal investigación objetivó comprender la práctica de esos profesionales en el Municipio de RecifePE. La metodología fue cualitativa de inspiración fenomenológica, anclada en la ontología heideggeriana. Los instrumentos utilizados fueron: entrevistas, grupo focal y diálogos con nueve participantes, además de las anotaciones de campo. Las narrativas fueron transcritas integralmente, literalizadas (Schmidt, 1990) e interpretadas mediante la analítica del sentido (Critelli, 2007). La práctica se caracterizó por la coexistencia de los siguientes aspectos: largo período de convivencia de pacientes y familiares, involucramiento afectivo y proximidad entre profesionales de la salud, familiares y niños, además de la intensidad en lo que respecta a los vínculos establecidos. Tales dimensiones repercuten en los modos de ser y de estar en el mundo de las participantes, haciendo la práctica transitar entre las dimensiones óntica y ontológica del cuidado. Con el tiempo, la práctica tiende a anclarse en las experiencias de coexistencia. Ejercicio ético de acogimiento a la alteridad, imposibilidad de control de los sucesos, además de la inminencia de muerte, dominan tal práctica, llevando a los profesionales a romper acciones separadas, a redimensionar el saber hacer y a reinventar modos intervencionistas por medio de la experimentación cotidiana.

Palabras clave: Cuidado. Psico-oncología pediátrica. Práctica (Psicología). Muerte.

\section{O câncer continua sendo uma doença temida} pela humanidade, e, não raro, é considerado sinônimo de morte, sofrimento e estigma. Ocorrendo na infância, parece adquirir uma conotação ainda mais intensa, tendo em vista o sentimento de piedade e de perplexidade dos adultos diante da precocidade do evento. Venâncio comenta que
Apesar dos avanços da Medicina no tratamento do câncer e do aumento de informações veiculadas pela mídia, o câncer ainda equivale, muitas vezes, a uma 'sentença de morte', comumente associado à dor, sofrimento e degradação. A literatura nos mostra que o câncer sempre foi percebido como algo vergonhoso, sujo, contagioso e sem cura, sendo uma doença tradicionalmente relegada pela sociedade. 


\begin{abstract}
O diagnóstico de câncer e todo o processo da doença são vividos pelo paciente e pela sua família como um momento de intensa angústia, sofrimento e ansiedade. Além do rótulo de uma doença dolorosa e mortal, o paciente comumente vivencia no tratamento, geralmente longo, perdas e sintomas adversos, acarretando prejuízos nas habilidades funcionais, vocacionais e incerteza quanto ao futuro. Muitas fantasias e preocupações em relação à morte, mutilações e dor encontram-se presentes (2004, p. 56)
\end{abstract}

Assim, a coexistência dos profissionais de saúde com a criança portadora de câncer vai sendo permeada por incógnitas, medos e fantasias, inclusive em relação aos psicólogos. Com base na experiência como psicóloga em um serviço público de oncologia pediátrica $(\mathrm{OP})$, alguns questionamentos oriundos desse contexto emergiram ao longo dos anos, por exemplo: como o psicólogo que atende crianças com câncer vivencia essa prática? Como se sente ao cuidar da criança doente? Como se dispõe a cuidar dessa criança e de seus familiares? Esses questionamentos alicerçaram o interesse por uma pesquisa de doutorado a partir de uma perspectiva fenomenológico- existencial em Psicologia.

Um dos elementos-chave para os questionamentos supracitados originou-se de observações na prática cotidiana da OP em um estágio de curso de pós-graduação. Nessa ocasião, constatamos que alguns psicólogos evitavam o contato com as crianças com câncer, afastando-se do setor de pediatria em virtude de um notável envolvimento emocional. Até o momento, a literatura especializada vem corroborando tal observação, haja vista que o contato direto com seres humanos coloca o profissional de saúde diante da própria vida, da saúde ou da doença, dos próprios conflitos e frustrações, podendo levá-lo a distanciar-se de quem cuida devido às tensões provenientes das fontes de seu trabalho, como, por exemplo: contato frequente com a dor, com o sofrimento e com pacientes terminais, receio de cometer erros e relações com pacientes difíceis (Mota, Martins, \& Véras, 2006). Sendo assim, cuidar de quem cuida parece ser condição necessária para desenvolver projetos de ações em prol de uma assistência de qualidade e da reflexão sobre a práxis em saúde. Tais ações, apesar de serem situações preconizadas pelo Sistema Único de Saúde (SUS) no Brasil, ainda carecem de maiores discussões no campo da Psicologia, principalmente em se tratando do setor de alta complexidade sanitária, como é o caso da OP.

Diante disso, elegeu-se como foco desta pesquisa o cenário das práticas psicológicas em OP, que tem sido pesquisado/documentado, sobretudo, a partir da década de 90. Exemplo disso são os estudos publicados por Santos (2002), Carvalho (1994, 2002), Valle (1994, 2004) e Françoso (1993, 1996), que enfatizaram o impacto do diagnóstico e do tratamento oncológico infantil, os grupos de familiares de pacientes em OP bem como a espiritualidade e suas influências no tratamento do câncer. Para tanto, partiu-se da ontologia fundamental, de Martin Heidegger (1999), e da compreensão da prática psicológica em seu processo fenomênico de des-velamento, ou seja, segundo a perspectiva heideggeriana de que o homem é um ser-nomundo (Dasein ${ }^{1}$ ) que ora se mostra, ora de oculta a partir dos modos de estar-no-mundo e da linguagem. Dessa forma, a prática foi discutida com base na experiência narrada dos participantes do estudo.

A palavra prática deriva do grego prássein, praktiké, e quer dizer fazer, agir, praticar, denotando o que dirige a ação, o que pode traduzir-se em ação e o que é racional na ação (Abbagnano, 1998). Em outras palavras, refere-se à experiência, habilidade, performance que se adquire com o treino de algo, habilidade, exercício de um ofício. 
Designamos práticas psicológicas em saúde as ações discursivas e provocadoras de formas de subjetivação na contemporaneidade (Medeiros, Guareschi, \& Bernardes, 2005). Com isso, a prática refere-se ao saber-fazer cotidiano narrado por meio da experiência humana; é uma espécie de composição forjada a partir da vivência cotidiana, dos saberes tácitos e da postura reflexiva que se origina a partir de seus desdobramentos.

\section{O câncer infantil e a prática psicológica}

O câncer traz algumas repercussões para a criança e seus familiares, tais como o impacto do diagnóstico e seus significados e o afastamento da criança do ambiente familiar e da escola devido aos longos períodos gastos entre exames e internação hospitalar, dentre outras modificações biopsicossociais a curto, médio e longo prazo. Durante o tratamento oncológico infantil, há momentos de estresse vivenciados por todos os envolvidos, inclusive pelos cuidadores (familiares, profissionais da equipe de saúde). As fases mais críticas do tratamento costumam ser: 1) o surgimento e o diagnóstico da doença, acompanhado por negação, raiva, ressentimento e culpa, 2) o momento do internamento hospitalar, marcado por medo, ansiedade e temor ao desconhecido, 3) as complicações e os possíveis fracassos do tratamento, 4) o retorno/ recidiva da doença, que costuma despertar forte angústia, tristeza, apatia e depressão, 5) as dúvidas quanto a escolhas de condutas terapêuticas a seguir e 6) os cuidados paliativos administrados, que nem sempre vêm acompanhados pela aceitação do fato (Wasserman, 1992 como citado em Chiattone, 1998).

Diante da complexidade de tal evento, costuma-se recomendar que o tratamento oncológico infantil se desenvolva de modo multidisciplinar e integrado. Braga,
Latorre e Curado (2002) e Garófolo (2005) contextualizaram e reuniram os seguintes dados sobre o câncer infantil:

- É a principal causa de mortes em crianças nos países desenvolvidos (UICC, 2008);

O câncer infantil compreende 0,5\% a 3,0\% de todas as neoplasias malignas humanas na maioria das populações, com incidência anual de 200 mil casos em todo o mundo;

As principais regiões com prevalência de câncer infantil são: Uganda, na África, Croácia, Nova Zelândia, Dinamarca, Estados Unidos e Canadá;

Os tumores mais comuns da infância são: leucemias (30,0\%), tumores do sistema nervoso central $(19,0 \%)$, linfomas $(13,0 \%)$, neuroblastoma $(8,0 \%)$, sarcomas de partes moles $(7,0 \%)$, tumor de Wilms $(6,0 \%)$, tumores ósseos $(5,0 \%)$ e retinoblastoma $(3,0 \%)$;

A maior incidência é no sexo masculino, havendo $70 \%$ de chances de cura em casos de diagnóstico precoce e tratamento especializado (INCA, 1997).

Segundo a União Internacional de Combate ao Câncer (UICC, 2008), a cada ano, mais de 160 mil casos de câncer infantil são diagnosticados, e 90 mil crianças morrem de câncer. Em todo o Planeta, cerca de 25 milhões de pessoas têm câncer. Além disso, $80 \%$ das crianças com câncer vivem em países em desenvolvimento, onde o tratamento efetivo nem sempre ocorre, embora uma dentre duas crianças consiga sobreviver.

Em 2007, segundo o Sistema de Informação de Saúde e Desenvolvimento Europeu (ENHIS), foi constatado que a leucemia é a neoplasia mais comum na infância, e corresponde a $30 \%$ de todos os cânceres diagnosticados em crianças abaixo de 15 anos. Em países europeus, uma em cada 500 crianças 
diagnosticadas com câncer tem até 15 anos, inclusive as crianças são mais propensas a eventos potencialmente relacionados à exposição de agentes cancerígenos externos (excesso de radiação, por exemplo), que podem refletir-se na ocorrência de um câncer.

O último levantamento epidemiológico do câncer infantil feito pelo INCA em 1997, órgão de referência no tratamento do câncer no Brasil, divulgou que as neoplasias malignas mais frequentes na infância são: leucemias (principalmente a leucemia linfóide aguda), tumores do sistema nervoso central, linfomas (tumores do sistema linfático), tumores renais (tumor de Wilms), neuroblastoma (tumor de glânglios simpáticos), retinoblatoma (tumor da retina do olho), osteosarcoma (tumor ósseo) e tumores germinativos e sarcomas (tumores de partes moles). Sobre isso, Reis, Santos e Thuler afirmaram:

No Brasil, ainda são poucos os trabalhos que abordam temas relacionados à epidemiologia dos tumores pediátricos. As informações sobre incidência do câncer provêm dos Registros de Câncer de Base Populacional (RCBP). Atualmente, há no Brasil 22 RCBP implantados; destes, 17 contêm informações consolidadas disponíveis para análise. Essas informações foram obtidas a partir de um aplicativo informatizado, desenvolvido pelo Instituto Nacional de Câncer (INCA), para entrada e consolidação dos dados colhidos pelos RCBP, o SisBasepop. Observa-se, em geral, uma predominância dos casos de leucemias, que variam de $15 \%$ a $45 \%$ de todos os tumores pediátricos, seguidos dos linfomas (5\% a $25 \%$ ) e de tumores do sistema nervoso central ( $5 \%$ a $22 \%$ ). Conclui-se ressaltando que é viável obter dados de incidência de câncer pediátrico, em larga escala, a partir dos RCBP (2007, p. 05)

O INCA, contudo, ressalta que houve um avanço considerável no tratamento do câncer infantil nas últimas quatro décadas, pois, atualmente, cerca de $70 \%$ das crianças acometidas de câncer podem ser curadas, se diagnosticadas de modo precoce e tratadas em centros especializados.

O exercício da Psicologia nesse cenário da oncologia e, mais especificamente, da OP é uma prática legitimada e assegurada por lei no Brasil (Portaria n.o 3.535, do Ministério da Saúde, de 14/10/1998), sendo chamada por alguns autores de psicooncologia (Carvalho, 2002; Costa Júnior, 2001; Bearison \& Mulhern, 1994). É coletiva em sua execução e desafiadora em seu contexto; afinal, tudo parece intensificado pelo longo convívio dos atores envolvidos, pela perplexidade evocada e pelas implicações da doença e do tratamento.

Diante do exposto, objetivou-se compreender a prática de psicólogos em OP na cidade do Recife-PE e suas implicações para os profissionais em questão. Trata-se, portanto, do recorte de uma pesquisa maior de doutorado, que foi realizada em cinco serviços especializados com nove psicólogas participantes (denominadas colaboradoras).

\section{Métodos}

Esta se trata de uma pesquisa qualitativa de orientação fenomenológica. Considerouse, portanto, as experiências das nove psicólogas colaboradoras bem como as implicações oriundas do contato com o campo. Assim, a forma de abordar o tema priorizou o recolhimento das experiências das colaboradoras por intermédio do diálogo e da interpretação (Schmidt, 2006; Duarte, 2008).

Inicialmente, a pesquisa foi submetida e aprovada no Comitê de Ética em Pesquisa da Sociedade de Combate ao Câncer de Pernambuco sob o número CAAE 0051.0.447.447-10. As nove participantes 
2 Colheita de dados é um termo utilizado na metodologia fenomenológica em vez de coleta de dados, pois presume-se que a palavra coleta dê a ideia de ir ao encontro de algo que já existe ou está pronto. Já colheita nos remete ao sentido de coconstrução processual dos dados, na qual o pesquisador recolhe as experiências dos participantes através de uma relação dialógica. provinham de cinco instituições distintas, sendo quatro da esfera pública e uma da esfera privada, e, mesmo assim, só uma profissional que tinha menos de um ano na prática deixou de participar, ou seja, atingiuse o número quase que total de psicólogas atuantes naquele período de realização da pesquisa (2009 a 2011). Apenas uma das participantes não pôde continuar até a fase final da pesquisa por motivos de ordem pessoal, tendo realizado apenas a entrevista inicial. As oito demais continuaram, sendo que duas não puderam participar do grupo focal devido à incompatibilidade de horários. As seis demais participaram de todas as etapas, que incluíram: 1) entrevista inicial com pergunta norteadora, 2) grupo focal e 3) diálogos seguidos por anotações de campo.

Os cuidados éticos envolveram a assinatura do Termo de Consentimento Livre e Esclarecido (TCLE) e a prévia emissão de cartas de anuência de todas as instituições participantes. As colaboradoras foram informadas quanto aos procedimentos metodológicos utilizados, sendo-Ihes atribuídos nomes fictícios por uma questão de sigilo.

Os critérios de inclusão das colaboradoras na pesquisa foram: estar empregada ou ser uma prestadora de serviço em instituições públicas ou privadas de OP e possuir pelo menos um ano de prática nessa área e estar trabalhando (diretamente) no campo da assistência às crianças com câncer. Todas foram previamente informadas sobre os objetivos e os procedimentos usados ao longo da pesquisa.

Os instrumentos utilizados para a colheita de dados ${ }^{2}$ foram: 1) diários de campo contendo registros das observações realizadas in loco, 2) entrevistas individuais contendo pergunta norteadora: "como é para você trabalhar com crianças que têm câncer?" e 3) grupo focal com o tema prática psicológica em OP.

Os procedimentos utilizados foram: 1) contato com as instituições e as profissionais envolvidas na OP a fim de apresentar a pesquisa, marcar entrevistas individuais e grupo focal, 2) emissão e recebimento das cartas de anuência de cada instituição participante, 3) assinatura do Termo de Consentimento Livre e Esclarecido (TCLE) pelas colaboradoras, 4) visitas institucionais e registros em diário de campo, 5) realização de entrevistas individuais e grupo focal com gravação em áudio mp3, 6) transcrição, literalização e envio das entrevistas via correio eletrônico para cada colaboradora, 7) obtenção de devolutiva de todas as colaboradoras via email e de forma presencial, 8) encontros individuais e em minigrupos para dialogar sobre a pesquisa e devolver resultados parciais e 9) análise dos dados.

As técnicas utilizadas incluíram a narrativa segundo a ótica de Walter Benjamin (18921940) e a literalização (Schmidt, 1990). A narrativa se interessa pela investigação da experiência como dimensão existencial do vivido (Dutra, 2002); já a literalização consiste em transformar as narrativas orais (falas) em um texto literário, ou seja, é uma edição das narrativas que conserva seu sentido original, suprimindo repetições excessivas e condensando relatos em parágrafos que versam sobre o mesmo assunto.

Assim, a obtenção dos dados se processou com a efetivação da leitura e a reflexão das entrevistas (E), do grupo focal (GF), das observações de campo e das notas dos diálogos com as colaboradoras. Já a proposta de análise foi construída com base na 
... o trabalho de Kovács, Eslinger, Vaiciunas e

Souza esclarece:

"A possibilidade

de morte de

uma criança é

uma situação que pode favorecer a emergência de intensos sentimentos na equipe de cuidados" (2008, p. 26). analítica do sentido (Critelli, 2007), que deriva da ontologia heideggeriana e pressupõe que o ser muda porque não está preso às coisas, e que só se pode compreendê-lo em seu movimento fenomênico de aparecimento/desaparecimento. Em outras palavras, o fenômeno não se desvela totalmente porque sempre haverá um sujeito para o qual ele se mostra em diferentes perspectivas. Esse movimento fenomênico dos entes só se torna real quando simultaneamente: a) o ente é desocultado por alguém (propriedade), b) quando desocultado, é acolhido e expresso por meio de uma linguagem (acolhimento e revelação), c) quando revelado por uma linguagem, é visto e ouvido por outros (testemunho), d) quando testemunhado, é referendado/reconhecido como verdadeiro por sua relevância pública (veracização) e e) quando veracizado, é efetivado em sua consistência mediante a vivência efetiva e singular dos homens (autenticação) (Barreto, 2006, 2009).

\section{Resultados e discussão}

Cinco temáticas des-veladoras de sentidos da prática investigada se destacaram: 1) tempo, proximidade e intensidade: as marcas da prática psicológica em oncologia pediátrica, 2) pelas vias da experiência cotidiana: o cuidado em ação na oncologia pediátrica, 3) estar-com: as marcas do trabalho coletivo em oncologia pediátrica, 4) abertura para a transcendência como sustentação da prática psicológica em oncologia pediátrica e 5) formação em cena: psicólogos à deriva? Contudo, em virtude do recorte realizado, enfatizar-se-á apenas a primeira temática por esta se referir mais diretamente à dimensão do objetivo deste artigo.

Aspectos relacionados ao tempo, à proximidade e à intensidade foram vistos como diferenciais da prática em
OP, exercendo repercussão no modo de as psicólogas estarem com o outro no mundo.

Tem sujeitos com 35 ou 36 anos que continuam vindo ao ambulatório, que continuam se comportando como no passado, e quando têm qualquer dor de barriga, voltam para o oncologista pediátrico e para a psicologia também. Eu não sei se isso esbarra também na dificuldade de acesso ao atendimento psicológico na rede. (colaboradora 8 - GF)

Essa proximidade entre os atores envolvidos tende a gerar vínculos que, não raro, provocam sofrimento, sobretudo quando ocorre a morte. A esse respeito, o trabalho de Kovács, Eslinger, Vaiciunas e Souza esclarece: "A possibilidade de morte de uma criança é uma situação que pode favorecer a emergência de intensos sentimentos na equipe de cuidados" (2008, p. 26). Talvez isso ajude a compreender esse trânsito das colaboradoras entre as dimensões ôntica e ontológica, entre a proximidade e a distância, e até mesmo entre a abertura e o fechamento, os quais possibilitam diferentes modos de estar-no-mundo-com-as crianças.

Outra implicação dessa prática é que ela sofre, constantemente, influências dos significados atrelados ao câncer e aos seus possíveis desdobramentos, a exemplo da iminência de morte e das possibilidades de ressignificação da vida. Na vivência das colaboradoras, isso também constituiu aspecto significativo: $-A$ doença também traz benefícios no sentido de ter um cuidado maior consigo. Não só a criança, mas a família inteira, porque a família também é convocada a ter um cuidado a mais. (colaboradora 1-E); - A prática foi me ensinando a traçar outros caminhos, principalmente quanto a questões ligadas aos pacientes que estão morrendo. (colaboradora 5-E)

Tal fato remete à importância do compartilhar (através do ouvir e do dizer) sentimentos e pensamentos que mobilizam os atores envolvidos na OP. Compartilhar situações 
que envolvem saúde-doença, morte-vida, dor-alegria é algo que favorece que crianças/ familiares se aproximem de seus projetos existenciais. É no cotidiano das interações que cada um vai se re-apropriando do seu poder-ser-si-próprio. Esse compartilhar se refere tanto aos encontros entre psicólogas com pacientes e familiares/acompanhantes quanto à relação dessas com a equipe de saúde.

A proximidade e o longo período de tempo, ao mesmo tempo em que caracterizam a prática, também foram percebidos como elementos que ora dificultam, ora facilitam o saber-fazer cotidiano.

Uma coisa que dificulta o nosso trabalho na OP e na oncologia de modo geral é esse contato que a gente tem muito longo com esse paciente. Não é um paciente que você vê duas ou três vezes, é um paciente que fica anos a fio com você. Tenho pacientes que começaram comigo crianças e hoje estão casados e já têm filhos. Então a gente não perde e não quebra esse elo. Essa é uma coisa que dificulta um pouco o trabalho, o lidar no dia a dia com os pacientes, seja com adultos, seja com crianças. A gente estabelece elos muito fortes com eles e com as famílias e não tem como não fazer isso; a gente participa das dores, das alegrias e dos acontecimentos da família, do batizado, do aniversário, dos 15 anos. (...) Tem uma coisa que também dificulta esse trabalho na $O P$, é que você fica tão envolvida que você precisa aprender a ter seu tempo também! Você não pode levar as coisas para casa. Não pode levar as coisas de casa para o trabalho nem as coisas do trabalho pra casa! (...) Não é um trabalho fácil! (colaboradora 8-E)

Temos a oportunidade de acompanhar o paciente desde o início e conhecê-lo mais de perto até o final do tratamento; isso facilita! São vínculos que se formam, e o vínculo é importante para o trabalho. $O$ psicólogo cria uma relação de confiança com o paciente e com a família. Existem vários desafios nessa área, como o de lidar com nossas questões emocionais, pois estamos lidando com a morte. Tem que ter o cuidado para não se tornar muito acostumado com as situações. As situações não podem me tirar de tempo, mas, ao mesmo tempo, as situações não podem deixar de mexer comigo, porque, se deixar de mexer comigo, eu não serei uma boa profissional. É um desafio teórico, mesmo quando tenho muito o que fazer. Tem que estudar, e às vezes não dá tempo por conta desse corre-corre. Tem que ter mais tempo! (colaboradora 9-E)

É importante ressaltar que a prática é atravessada por esse movimento de aproximação-envolvimento e afastamento reflexivo. Tal movimento busca resguardar os princípios éticos e a privacidade dos envolvidos, conforme atestam algumas narrativas: - Quando saí da faculdade, a teoria era toda arrumadinha. E a prática vai ensinando a gente a tomar outros caminhos, a criar outras saídas para algumas situações. A gente não pode misturar as coisas, porque senão corre-se o risco de se perder nessa relação! (colaboradora 8-E); - Quando falei de sensibilidade, também falei em técnica. Essas duas coisas acontecem na oncologia pediátrica. Você começa a identificar quando percebe o sentimento, que é vivencial. E quando tem uma técnica, você tenta olhar para esse sentimento também. Há como se misturar e se afastar, não é? Então é essa aproximação e esse afastamento. (colaboradora 2)

Isso fica mais claro com o relato de algumas colaboradoras ao discorrerem sobre a impossibilidade de uma prática distanciada e dissociada do humano em suas demandas existenciais, bem como da possibilidade de afetar-se e de ser afetado: - A gente tem que lembrar que o profissional também tem sentimento. Nem tudo é maravilhoso, vejo uma criança ali sofrer! (colaboradora 1-E); Tem afeto, porque você convive, você sabe a história, você sabe quem é o pai, quem é a mãe, sabe tudo... Você tá convivendo 5 meses, 6 meses, 1 ano! (...) É eu não me misturar ao 
ponto de comprometer um trabalho. Seria uma espécie de neutralidade relativizada. (colaboradora 2-E); - Eu não quero achar normal ver a dor de uma pessoa (...) Quando estou trabalhando, eu me envolvo tanto que, quando eu tenho que ligar para casa, coloco o alerta no celular para me lembrar, porque senão esqueço. (colaboradora 4-E); - Estou vendo que minha prática não é a mesma daquela que tive na clínica da faculdade. Aqui é uma coisa mais humana, que exige muita doação. (colaboradora 6-E); - Antes eu tinha aquela coisa de muita neutralidade, e no hospital isso é diferente, pois estou bem mais próximo do paciente e da família, o que transforma a prática (...) A forma como lido e olho para os pacientes é diferente, não tem aquela coisa de neutralidade absoluta! (colaboradora 7-E).

Ao longo de seu desdobrar-se, a prática vai sofrendo modificações em virtude das demandas do contexto e dos próprios profissionais. Com o tempo, as teorias e algumas posturas acadêmicas são redimensionadas, e a prática passa a sustentarse, principalmente, na atitude investigativa da experiência, já que condutas tecnicistas não dão conta da complexidade da OP. Com isso, rompe-se a suposta neutralidade, e o saberfazer passa a ser balizado por um dado ethos. Tal ethos se fundamenta no acolhimento da alteridade que não se deixa capturar/reduzir aos ideais ou às leis de conduta universal (Andrade \& Morato, 2004).

Algo que chamou a atenção foi a possibilidade que as profissionais expressaram de encarar e de acolher tal prática com seus paradoxos, examinado o próprio trabalho de modo crítico e reflexivo e reconhecendo a impossibilidade de controle absoluto sobre os acontecimentos da prática cotidiana.
É tão contraditório falar em satisfação nesse contexto da oncologia pediátrica! Mas existe satisfação quando vejo meu trabalho surtindo efeito. É um trabalho que tem retorno! Retorno não só do paciente que já começa a me procurar para conversar e a família que começa a se sentir mais tranquila. É esse retorno que traz satisfação! (colaboradora 9-E)

Os sentimentos que me visitam com frequência em minha prática são angústia, tristeza e compaixão. Eu acho que são exatamente esses três que fazem parte! (colaboradora 1-E)

O sentido de minha prática está em trabalhar com as dificuldades que as pessoas têm e acompanhá-las. (colaboradora 7-E)

Já passei por vários questionamentos como: 'por que eu escolhi fazer isso? Não podia fazer turismo ou uma coisa mais light?' (...) Um problema do trabalho do psicólogo na OP e no trabalho do psicólogo como um todo é que a Psicologia é uma profissão extremamente solitária! As questões éticas te amarram muito, e você, que trabalha no câncer, não vai comentar, porque ninguém quer ouvir: 'ah, hoje eu atendi um paciente com tumor, assim e tal'. Ninguém quer ouvir isso, e dizem: 'ah, vamos mudar de assunto? Que tal a gente falar de outra coisa? Seu trabalho é muito pesado, não quero saber de seu trabalho, não!' Por isso, a gente acaba se sentindo angustiada porque se fala tão pouco! (colaboradora 8-E)

Para lidar com tais paradoxos e desafios, algumas colaboradoras se referiram à criação de estratégias de enfrentamento, tais como trocas e diálogos com a equipe, atividades de lazer, cuidado com a saúde, momentos de ócio, psicoterapia e supervisão. Todos foram descritos como elementos indispensáveis para a sustentação de uma prática eficaz e comprometida. O autocuidado foi apontado como uma das principais ferramentas para a retroalimentação da prática e do cuidado de ser.

Eu tenho buscado investir em minha qualidade de vida: procuro ter hábitos saudáveis, como uma boa alimentação 
e respeitar minhas horas de sono. Compareço a consultas médicas e faço exames periodicamente, faço psicoterapia há anos (...) Cuido de mim porque passo a me conhecer melhor, saber mais de minhas necessidades. (colaboradora 7-GF)

Você tem que ter uma válvula de escape que dê pique para também pensar em si mesmo, em se refazer, em recarregar as baterias para trabalhar melhor. A maneira pela qual eu faço isso é através do lazer. Eu adoro ir ao barzinho tomar cerveja, gosto de ir à praia, ao cinema e viajar. Adoro viajar! E um dos meus hobbies favoritos! Gosto de ler, assistir filmes, de cuidar das minhas coisas. Eu acho que não tem coisa que me dá mais prazer que cuidar das minhas coisas! (colaboradora 8-E)

Eu me trato pessoalmente no que diz respeito ao trabalho que faço aqui. Eu faço

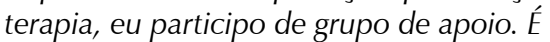
desgastante, mas eu me trato na medida do possível, porque eu faço terapia, eu participo de grupo de apoio, a gente 'troca'. Como é que a gente troca? A gente se encontra! (colaboradora 1-E)

Tem que estar inteira e sempre buscando e estudando! Faço terapia há muito tempo, e sempre descubro coisas e cresço muito! Quando comecei a trabalhar no hospital, comecei a cuidar mais de minha saúde física. Em outro tempo, não cuidava muito de minha alimentação, hoje em dia, estou mais atenta, não pulo refeições e faço exames a cada seis meses. (colaboradora $7-\mathrm{E})$

Para me cuidar, eu procuro ver coisas bonitas, até para oxigenar a cabeça e ficar bem no dia seguinte. (colaboradora 3-E)

Assim, percebemos que, na dimensão ôntica, a base para o exercício do psicólogo encontrase no cuidar do outro e no cuidar de si mesmo. Sem o cuidado e o autocuidado, a prática em OP possivelmente não se sustentaria por si só, tendo em vista os imperativos éticos suscitados nas experiências narradas. Em outras palavras, a prática gera a necessidade de um cuidado de si mesmo, a delimitação e o cultivo de um espaço para si mesmo, o reconhecimento de limites e a luta por um espaço de cultivo do ócio.
Vejo que meu trabalho teve interferências no modo como eu me cuido. O fato de falar muito e de estar o tempo todo questionando 'será que esse paciente está se cuidando?' vai me deixando atenta ao que estou ouvindo e construindo verdades em minha cabeça de uma forma mais apropriada. Como vou falar uma coisa que não faço? Se assim fosse, eu não estaria sendo verdadeira na relação. Como falo uma coisa para os pacientes se estou vivendo outra coisa completamente diferente? Então eu acredito que esse trabalho me trouxe autoconhecimento e me deixou mais cuidadosa! (colaboradora 7-E)

Eu também tenho que ter um tempinho para minha yoga, para o relaxamento e para não fazer nada. (colaboradora 1-E)

Diante desse cenário, há narrativas que atestam o quanto essa prática é tecida a partir da experiência cotidiana e dos saberes tácitos (Figueiredo, 1996).

Quando eu cheguei de manhã no hospital, o paciente não estava mais lá (referindo-se ao óbito). Isso é uma coisa que foge do que aprendi na teoria, mas a prática do dia a dia acaba ensinando a fazer (...) O trabalho do psicólogo tem algo de intuitivo, porque você lida com sentimento o tempo todo. É o que rola na relação! É a relação de confiança que estabeleço. As pessoas vão falar dos medos mais profundos que têm na vida! (...) Às vezes é preciso construir e criar situações. E só a prática te dá isso! Não tem livro que te dê isso! A prática e o dia a dia é que faz você descobrir isso! (...)Tem coisas que acontecem que os livros não ensinam. (colaboradora 8-E)

Não é receita de bolo! Não basta pegar um livro! Tem que processar, conhecer a história do paciente e daquela família para poder saber dar um retorno. Não tem receita de bolo para processar isso. É ouvir e ir atender! (colaboradora 3-E)

Você não tem respostas prontas, e você tem que ter essa consciência. Eu acho que as pessoas tendem a ter respostas prontas. (colaboradora 4-E) 
A ideia de que a prática se constrói com base em conhecimentos explícitos/científicos e também em torno de conhecimentos implícitos/tácitos corrobora o que Figueiredo observa a respeito da profissão do psicólogo e que coincide com o posicionamento de Susaki, Silva e Possari (2006) ao afirmarem que o conhecimento utilizado na prática dos profissionais de saúde é fruto da experiência cotidiana.

Há outras implicações dessa prática que incidem diretamente/indiretamente na vida dos seus protagonistas e que têm desencadeado amadurecimento, cultivo de virtudes, autocuidado, solidariedade, resiliência, aprendizado e aperfeiçoamento da escuta clínica:

Passei a ver a vida de outra maneira, porque eu era uma pessoa, e depois que comecei a trabalhar aqui, eu sou outra pessoa completamente diferente, no sentido de dar mais valor à vida, às pessoas que estão próximas de mim! (colaboradora 6-E)

Trabalhar com essas crianças trouxe amadurecimento! Percebi que minha escuta melhorou, inclusive minha experiência no trabalho clínico ficou diferente, mais livre e com mais possibilidades de aproximação. (colaboradora 7-E)

Vivenciamos situações que são verdadeiras lições para toda a vida, e não há dinheiro no mundo que pague isso (...) Valorizo muito mais as pequenas coisas, como o bem-estar das pessoas. Eu não imagino o que seria e a forma como eu seria se não trabalhasse em oncologia pediátrica. (colaboradora 4-E)

Esse trabalho trouxe para mim essa coisa de não valorizar tanto os meus problemas, de entender que eu preciso cuidar de mim também, porque se não, adoeço. Aprendi a exercitar essa disponibilidade para com o outro, a desenvolver tolerância e paciência. (...) Quanto aos benefícios que esse trabalho me trouxe, destaco que, por exemplo, eu descobri que meus problemas são muito pequenos! (colaboradora 8-E)

Se eu gostava de viver, hoje eu gosto mais ainda! Sou apaixonada pela vida! Adoro viver, hoje mais ainda! Valorizo as pequenas coisas, e não fico ligada só a trabalho, mas procuro preservar amizades e estar junto com minha família. (colaboradora 5-E)

A minha humanidade é cuidada quando atendo os pacientes e familiares na $O P$. (colaboradora 9-E)

A partir disso, questiona-se: será que tais implicações têm a ver com o que Rego e Palácios (2006) disseram a respeito do poder que a morte tem de humanizar as pessoas? Será que o convívio direto com a iminência de morte não convoca as psicólogas a se lembrarem de sua condição mortal? E, ao experimentar a consciência da finitude, elas não estariam criando outras possibilidades de atuação? De qual forma esses impactos vão repercutindo na prática em OP? Além disso, observou-se que essa prática também exige a incorporação de novos conhecimentos oriundos de vários campos de saber, a exemplo de termos médicos, da oncologia, da imunologia. Assim, a prática foi narrada a partir de sua característica eminentemente transformadora.

Percebo mudanças em minha prática. Hoje estou mais à vontade e não me questiono mais como me questionava no começo. (colaboradora 9-E)

Gostei dessa mudança, mas foi sofrido e ainda é! Mas foi bom! Acho que nada na vida é por acaso, se eu vim aqui, foi para perceber a minha vida de outra maneira. (colaboradora 6-E)

O que mudou nisso tudo? Nossa, mudou muita coisa! Mudou minha visão de mundo, de vida, de tudo. Mudei como pessoa. (colaboradora 4-E)

A experiência de contato direto com as crianças e seus familiares vem possibilitando a incorporação de novos saberes em prol do cuidado. Essa questão aponta discussões que vão muito além do proposto, mas que acenam para a multi/inter e a transdisciplinaridade em 
saúde. Às vezes o modelo mais praticado é a multidisciplinaridade, já que a execução da inter e da trans-disciplinaridade exige articulação e diálogo constante entre os membros da equipe de saúde, que, não raro, se encontram isolados e esgotados em seu cotidiano de trabalho. Em OP, apesar das dificuldades apontadas pelas colaboradoras, parece haver interlocuções entre as equipes, ora pelo viés multidisciplinar, ora pelo viés interdisciplinar, já que o câncer infantil exige, por si só, um trabalho coletivo.

Essa forma da gente trabalhar em uma equipe multi, trabalhar de forma interdisciplinar, é privilegiada. A gente ainda conseguiu uma reunião com a equipe multiprofissional toda quartafeira junto com a nutrição, a terapia ocupacional e a Psicologia para ver as coisas que não estão andando legal, resolver alguma coisa. Isso dá aquela sensação que você faz parte da equipe! (colaboradora 4-GF)

Nunca tive dificuldades (desde que entrei na instituição) com a equipe que trabalho, porque eles solicitam o trabalho do psicólogo, dividem as questões com a gente, trabalhamos até com a própria equipe, com as necessidades dos profissionais, com as dificuldades de relacionamento. Eu acho que existe essa abertura. (colaboradora 5-GF)

Eu acho que é um trabalho realmente de equipe multidisciplinar, e não tem como ser diferente. Há tanto a valorização da gente (como psicólogo) como a valorização dos outros profissionais; reconhecemos essa importância. Às vezes também dentro da mesma instituição e em outros setores, eu não percebo isso tanto, mas na oncologia, eu vejo. Você não vê ninguém fazer oncologia sozinho! (colaboradora 2-GF)

Não houve um consenso quanto às especificidades da prática com crianças e com adultos com câncer. Aquelas que enfatizaram especificidades também destacaram elementos diferenciadores, tais como: o uso de recursos lúdicos e da criatividade, o resgate da sensibilidade e a criação de estratégias facilitadoras de expressão oral, tais como desenhos, estórias e jogos.

A especificidade de minha prática é sempre lembrar que a criança é criança. (colaboradora 3-E)

A prática em OP é específica no sentido de usar mais da criatividade (bonecos, fantoches e, às vezes, até o celular) para demonstrar os procedimentos, pois, muitas vezes, esse é o único material que a gente tem! (colaboradora 1-E)

É importante, no trabalho com crianças, a sensibilidade e o resgate do lúdico, pois, no hospital, essa coisa da criança fica um pouco de lado. A gente usa muito o lúdico e reconhece que essa é uma questão importante. (colaboradora 7-E)

Outro elemento que atravessa a prática cotidiana é a iminência de morte das crianças, que tende a afetar mais do que a própria morte do adulto.

Quando se trata de adultos, aceitamos melhor o momento de fechamento de sua vida, mas quando é uma criança que mal chegou, é muito mais difícil! Muitas vezes, a mãe faz o questionamento: 'por que ele vai morrer? Por que ele morreu, se nem chegou a viver?' Então você vai explicar àquela mãe o que aconteceu, mas isso Ihe deixa uma reflexão: por que? Procuro arrumar esses por quês perfeitamente, até porque, se eu não conseguisse arrumar, eu não estava por aqui, não! (colaboradora 3-E)

A morte perpassa o cenário cotidiano da OP. E essa iminência de sua aparição a qualquer momento traz não apenas a consciência da finitude mas também leva as pessoas a se angustiarem diante das perdas relacionadas à vida, ao corpo e à experiência de estar neste mundo, inclusive o psicólogo (Kovács, 1991).

Quanto mais os profissionais de saúde ficam obcecados pela crença no ideal de vencer a morte, mais difícil se torna lidar com essa iminência de finitude. Quanto mais isso estiver arraigado no profissional, mais fácil 
3 Mito de Dâmocles: Dâmocles era um súdito da corte do rei Dionísio. Ele admirava o reino e, sempre que podia, expressava seu sonho de um dia poder ter à mão tudo o que desejasse. Ele insistiu tanto nesse desejo que Dionísio lhe concedeu que fosse rei por um dia, com direito a coroa, cetro, banquete e tudo o mais. Mandou, porém, colocar uma espada em cima do trono, presa por um fio de rabo de cavalo. Dâmocles exultou; finalmente seu sonho seria realizado! Vestiuse com pompa, assumiu a condição de rei e mergulhou no banquete em sua homenagem. Porém, no meio da festa, levantou os olhos e viu, sobre sua cabeça, a espada pendurada, que poderia a qualquer momento decepá-lo e, então, implorou ao rei que the permitisse abdicar daquela sorte, $\mathrm{e}$ imediatamente perdeu todo o interesse naquele lugar de honra, devolvendo o trono ao seu legítimo dono. será que se torne refém da lógica tecnicista (Poles \& Bousso, 2006). Nesta pesquisa, as colaboradoras pareciam familiarizadas com o contexto da morte, e, mesmo revelando dificuldades inerentes face à impossibilidade de cura, afirmaram a vida em seu poder-ser mais próprio em todos os momentos deste estudo.

Um elemento comum que define essa prática na OP é a escuta clínica, ou seja, a atitude de inclinar-se junto ao outro que procura ou é procurado. Um aspecto relevante, nesse sentido, é que tal escuta apareceu atrelada à orientação com os pais e acompanhantes, além do acompanhamento pós-óbito.

No trabalho em $O P$, temos que estar orientando as famílias para entenderem que a criança está doente e que não é um tratamento simples (...) Esse trabalho não é restrito ao paciente, e precisa estar inserido em nosso trabalho como uma conduta de rotina. (colaboradora 3-E)

Temos também o acompanhamento pós-óbito, que é oferecer a possibilidade dessas famílias trabalharem em cima de uma nova reestruturação, essa tentativa de reestruturar a vida, de viver sem esse filho! (colaboradora 4-E)

A prática também pareceu ser norteada pela disponibilidade afetiva em estar com o outro, pela tolerância e pela paciência. A disponibilidade já é ação, mas essa ação possui limites: - A prática psicológica com crianças que têm câncer tem que ser o dia a dia, é você se dispor. (colaboradora 4-E); O diferencial da prática do psicólogo em OP é a disponibilidade interna, a empatia para compreender o que é dito nas entrelinhas ou o que não é dito, o desejo de cuidar, o desprendimento e a coragem para lidar com a dor do outro e sua própria dor. (colaboradora 7-E); - Aprendi a exercitar essa disponibilidade para com o outro, a desenvolver tolerância e paciência. É um trabalho que faz com que você exercite isso o tempo todo. (colaboradora 8- E).
Sendo assim, percebeu-se que, na maior parte do tempo, a prática em OP requer o exercício dessa disponibilidade e movimento para acompanhar a existência do outro. E essa disposição se manifesta através de dois modos de ser: pelo temor/fechamento e pela angústia/abertura diante dos fenômenos (Heidegger, 1999). O trânsito por entre essas vias se desvelou como dimensão constitutiva da prática investigada.

\section{Considerações finais}

Sob a espada de Dâmocles ${ }^{3}$ ! É assim que uma das colaboradoras de nossa pesquisa descreveu sua prática cotidiana em OP, e é com essa metáfora que ousamos traduzir uma prática permeada por paradoxos e possibilidades, inclusive a de experimentar o poder-ser próprio diante de uma doença grave como o câncer. Tal cenário repleto de desasossego, angústia, sofrimento, finitude, cuidado, superação, solidariedade, dignidade e aprendizado, dentre outras vivências intensas, reporta-nos mesmo à experiência de Dâmocles ao experimentar o lugar do rei por um dia, usufruindo as possibilidades que isso lhe traria, e, ao mesmo tempo, tendo uma espada pendurada no teto e apontada sobre a sua cabeça. A vivência de essa possível ameaça/risco se concretizar, podendo causar danos/perdas a qualquer instante, inclusive a perda do poder, fez-nos recordar a iminência de morte das crianças com câncer, a qual tende (não raro) a des-fazer e a diluir o poder daqueles que cuidam - os profissionais de saúde, inclusive o psicólogo. Estes, por sua vez, figuram como os muitos Dâmocles em OP, cabendo-Ihes o poder ôntico da cura e o dever ontológico do cuidado das crianças com câncer, de seus familiares, da equipe e até de si mesmos. Contudo, esse poder-cuidar/curar está sob a ameaça constante da impossibilidade, correndo o 
risco de nem mesmo se concretizar ou de continuar existindo. Tal paradoxo nos ensinou que a prática psicológica em OP é um poder-cuidar/curar que está sob o risco da espada, anunciada aqui pelo cenário da OP e, principalmente, pelos dias em que a morte, o medo, a solidão, a dor e tantos outros acontecimentos ligados ao câncer assolam aqueles que se engajaram, assim como Dâmocles, no banquete do poder-cuidar/curar. O poder aqui pode ser compreendido como o saber-fazer de cada um dos profissionais de saúde e até mesmo o daqueles que se dispõem a encarar o lugar de Dâmocles (nem que seja por algumas horas) nos serviços de OP deste país, sejam eles pais, parentes, amigos, voluntários, estagiários, grupos religiosos, artistas ou empresários, dentre outros.

Assim, tal prática se mostrou como ação afirmativa que focaliza o que as crianças/ familiares e equipe podem e não o que não podem. Mesmo diante de um cenário tão complexo, as colaboradoras enfatizaram a possibilidade, a potência, o devir, o ainda não do outro, e isso não significa que elas neguem ou banalizem a morte. Ao contrário, isso exige que o psicólogo lide com situações limítrofes de um cenário onde a única certeza é a mudança.

Mesmo diante dos paradoxos, dos desafios e de uma prática inquietante, as colaboradoras não se esforçaram para livrar-se das incertezas e angústias que assolavam seus modos de estar com o outro. Isso contraria a lógica representacional do pensamento metafísico de previsão, fragmentação e controle excessivo. Com isso, questiona-se: o que faz que essas profissionais não sucumbam ao desejo de controle? Seria o reconhecimento de sua impossibilidade, já que se trata de uma área marcada pela iminência de finitude? Seria algo que as convoca a responder mediante seus posicionamentos éticos frente às pessoas envolvidas e ao mundo?

Em nenhum momento demonstraram incômodo pela incerteza ou pelo inesperado. Ao contrário, suas narrativas explicitaram que há lugar para o acolhimento do inesperado, do novo, do imprevisível. E isso confere uma potência transformadora da prática.

Com o tempo, essa prática tende a ancorar-se, cada vez mais, na própria experiência. Isso foi visto como um modo não só de superar as lacunas do processo formativo mas também como desdobramentos de um exercício ético que acolhe o outro tal como ele se apresenta. Assim, pode-se considerar que é uma prática que transita por entre as dimensões ôntica e ontológica do existir humano, ultrapassando a execução de procedimentos técnicos, pois, mesmo quando não é possível alcançar a remissão de sintomas, ainda assim é possível antecipar-se ao outro e cuidar de ser. Nessa ótica, as psicólogas não se ativeram à doença ou ao diagnóstico, mas às experiências do humano que adoece, as quais podem ser des-veladas através de uma escuta atenta e sensível. Em suma, seria uma prática que se aproxima da noção grega de técnica como techné (arte, invenção), tanto que a neutralidade não foi uma prerrogativa valorizada.

Sendo assim, essa pesquisa aponta a urgente necessidade de a Psicologia avançar no que diz respeito ao saber-fazer voltado para a média e a alta complexidade em saúde. As pesquisas ainda são escassas e, quando existentes, concentram-se na área da Enfermagem e da Medicina. Ademais, pouco ou quase nada é ofertado nos 
currículos dos cursos de graduação em Psicologia como alternativa para a discussão/ aprofundamento de temáticas dessa ordem. Mesmo compreendendo que grande parte da formação do psicólogo depende das escolhas de cada um, questiona-se: como os futuros psicólogos optarão por algo que sequer existe em seus currículos? Como redimensionar essa realidade em um país que legisla sobre a obrigatoriedade da presença de psicólogos em equipes de oncologia e onde o câncer constitui questão de saúde pública se nesse mesmo país não se oferece, para os profissionais de saúde, uma formação que pelo menos os introduza no preparo para a realidade da média/alta complexidade em saúde? Será que a recente inserção de psicólogos no setor público de saúde ainda não ocorreu de modo mais efetivo devido à falta de articulação da categoria e ao despreparo para tal? 


\section{Sílvia Raquel Santos de Morais}

Doutora em Psicologia pela Universidade Federal do Espírito Santo e docente da Universidade Federal do Vale do São Francisco, Petrolina - PE - Brasil.

E-mail: silviamorays@yahoo.com.br

\section{Ângela Nobre de Andrade}

Doutora em Psicologia pela Pontifícia Universidade Católica de São Paulo e docente da Universidade Federal do Espírito Santo, Vitória - ES - Brasil.

E-mail: anobre@terra.com.br

\section{Endereço para envio de correspondência:}

Rua Lucas Roberto de Araújo S/N ; Condomínio Sol nascente 3, Rua 9, № 171, Bairro Cidade universitária. CEP: 56332-720. Petrolina, PE

Recebido 13/12/2011, 1a Reformulação 17/01/2013, Aprovado 30/01/2013. 
Abbagnano, Nicola. (1998). Dicionário de Filosofia.(3a. ed.) revista e ampliada). São Paulo: Martins Fontes.

Andrade, A. N., \& Morato, H. T. P. (2004). Para uma dimensão ética da prática psicológica em instituições. Estudos de Psicologia, 9(2), 345-353.

Barreto, C. L. B. (2006). A ação clínica e os pressupostos fenomenológicos existenciais. Tese de doutorado. Programa de Pós-Graduação em Psicologia, Universidade de São Paulo, USP, São Paulo, SP.
Barreto, C. L. B. T., \& Morato, H. T. P. (2009). A ação clínica e a perspectiva fenomenológica existencial. In H. T. Morato C. L. Barreto \& A. P. Nunes (Coords.). Aconselhamento psicológico numa perspectiva fenomenológico existencial. Uma introdução. (Série Fundamentos em Psicologia). São Paulo: Guanabara Koogan.

Braga, P.E, Latorre, M.R.D.O; Curado, M.P. (2002). Câncer na infância: análise comparativa da incidência, mortalidade e sobrevida em Goiânia (Brasil) e outros países In Cadernos de Saúde Pública. São Paulo, SP. 18(1): 33-44. 
Brasil. Ministério da Saúde. Portaria no 3.535/GM publicada no Diário Oficial da União n o 196-E, Seção 1, pág. 53 e 54, de 14.10.1998. Recuperado em 26 fev. 2011, de http://dtr2001. saude.gov.br/sas/portarias/port98/GM/GM-3535.html

Bearison, D. J., \& Mulhern, R. K. (1994). Pediatric psychooncology - Psychological perspectives on children with cancer. N. York: Oxford University Press.

Carvalho, M. M. (1994). Introdução à psicooncologia. Campinas, SP: Psy II.

Carvalho, M. M. (2002). Psico-oncologia: história, características e desafios. Revista Psicologia da USP, 13(1), 01-08. Recuperado em 26 fev. 2009, de http://www.scielo.br/scielo. php?script $=$ sci_arttext\&pid $=$ S0103-

Chiattone, H. B. C. (1998). Urgências psicológicas em leucemias. In V. A. C. Angerami (Org.). Urgências psicológicas no hospital (pp.171-191). São Paulo: Pioneira.

Costa Júnior, A. C. (2001). O desenvolvimento da psicooncologia: implicações para a pesquisa e intervenção profissional em saúde. Psicologia: Ciência e Profissão, 21(2), 36-43.

Critelli, D. M. (2007). Analítica do sentido. Uma aproximação e interpretação do real de orientação fenomenológica (2a ed). São Paulo: Brasiliense.

Duarte, L. F. (2008). Um serviço de atenção psicológica à terceira idade: à pro-cura da demanda. Dissertação de mestrado. Programa de Pós-Graduação em Psicologia, Instituto de Psicologia da Universidade de São Paulo, São Paulo, SP.

Dutra, E. (2002). A narrativa como uma técnica de pesquisa fenomenológica. Revista Estudos de Psicologia, 7(2), 371-378.

Sistema de Informação de Saúde e Desenvolvimento Europeu/ Enhis.(2009). Incidence of childhood leukaemia. Fact Sheet, 4.1 z December 2009 z CODE: RPG4_Rad_E1. Recuperado em 02 fev. 2011 de http://www.euro.who.int/_data/ assets/pdf_file/0005/97016/4.1.-Incidence-of-childhoodleukaemia-EDITED_layouted.pdf

Françoso, L. P. C. (1993). Enfermagem: imagens e significados do câncer infantil. Dissertação de mestrado. Escola de Enfermagem da Universidade de São Paulo, Ribeirão Preto, SP.

Françoso, L. P. C. (1996). Reflexões sobre o preparo do enfermeiro na área de oncologia pediátrica. Revista Latinoamericana de enfermagem, 4(3), 41- 48.

Figueiredo, L. C. M. (1996). Revisitando as psicologias. Da epistemologia à ética das práticas e discursos psicológicos (2a ed. revista e ampliada). São Paulo: Educ/Vozes.

Garófolo, A. (2005). Diretrizes para terapia nutricional em crianças com câncer em situação crítica Rev. Nutrição. JulhoAgosto. Campinas, SP. 18(4): 513-527.Recuperado em 12 Abril 2009 de http://www.scielo.br/scielo.php?pid=S1415$52732005000400007 \&$ script $=$ sci_arttext.

Heidegger, M. (1999). Ser e tempo (Parte I, 8a ed.). Petrópolis, RJ: Vozes.

INCA. Ministério da Saúde. Instituto nacional do Câncer (1997). Coordenação de Programas de Controle de Câncer (PróOnco). O problema do câncer no Brasil. Rio de Janeiro: INCA

Kovács, M. J. (1991). Pensando a morte e a formação de profissionais de saúde. In R. M. S. Cassorla (Org.). Da morte: estudos brasileiros (pp. 79-103). Campinas, SP: Papirus.
Kóvacs, M. J., Eslinger, I., Vaiciunas, N., \& Souza, T. M. (2008). Cuidando do cuidador em UTIs pediátrica e neonatal. Revista Mundo da Saúde, 32(1), 24-30.

Medeiros, P. F. de, Bernardes, A. G., \& Guareschi, N. M. F. (2005). O conceito de saúde e suas implicações nas práticas psicológicas. Revista Teoria e Pesquisa, 2(3), 263-269.

Michelazzo, J. C. (1999). Do um como princípio ao dois como unidade. Heidegger e a reconstrução ontológica do real. São Paulo: FAPESP, Anablume.

Mota, R. A., Martins, C. G. M., \& Véras, R. M. (2006, maio/ agosto). O papel dos profissionais de saúde na política de humanização hospitalar. Psicologia em Estudo (online), 11(2), 323-330. Recuperado em 2 jun. 2011, de http://www.scielo. br/pdf/pe/v11n2/v11n2a10.pdf

Poles, K., \& Bousso, R. S. (2006). Compartilhando o processo de morte com a família: a experiência da enfermeira na UTI pediátrica. Revista Latino-Americana de Enfermagem, 14(2), 207-213.

Reis, R. S.; Santos, M.O.; Thuler, L.C.S. (2007). Incidência de tumores pediátricos no Brasil Rev Brasileira de Cancerologia [Online]. Rio de Janeiro, INCA. 53(1): 5-15. Recuperado em 4 Junho 2010 de http://www.inca.gov.br/rbc/n_53/v01/ pdf/artigo1.pdf.

Rego, S. \& Palácios, M. (2006). A Finitude Humana e a Saúde Pública. Cad. Saúde Pública [Online].Agosto.Rio de Janeiro. 22(8):1755-1760. Recuperado em 4 Junho 2009 de http://www.scielo.br/scielo.php?pid=S0102311X2006000800025\&script=sci_arttext.

Santos, M. E. M. (2002). A criança e o câncer. Desafios de uma prática em psico-oncologia. Recife, PE: Ag Botelho.

Schmidt, M. L. S. (1990). A experiência de psicólogas na comunicação de massa. Tese de doutorado. Instituto de Psicologia, Programa de Pós-Graduação, Universidade de São Paulo, São Paulo, SP.

Schmidt, M. L. S. (2006). Pesquisa participante: alteridade e comunidades interpretativas. Psicologia USP (online), 17(2), 11-41. Recuperado em 22 maio, 2011, de http://www. revistasusp.sibi.usp.br/pdf/psicousp/v17n2/v17n2a02.pdf

Susaki, T. T., Silva M. J. P., \& Possari J. F. (2006). Identificação das fases do processo de morrer pelos profissionais de enfermagem. Acta Paul Enferm. (online), 19(2),144-149. Recuperado em 25 maio, 2011, de http://www.scielo.br/ scielo.php?pid =S0103-21002006000200004\&script $=$ sci abstract\&tlng $=p t$

União internacional de combate ao câncer/UICC (2008). Site da UICC. Recuperado em 06 Agosto 2008. De http://www.uicc. org/index.php?option $=$ com_frontpage\&Itemid $=1$

Valle, E. R. M. (1994). Vivências da família da criança com câncer. In M. M. Carvalho. Introdução à psicooncologia. Campinas,SP: Psy II.

Valle, E. R. M. (2004). Acompanhamento psicológico em oncologia pediátrica. In W. A. Angerami-Camon (Org.). $O$ atendimento infantil na ótica fenomenológico-existencial. São Paulo: Thomson.

Venâncio, J. (2004). Importância da atuação do psicólogo no tratamento de mulheres com câncer de mama. Revista Brasileira de Cancerologia - INCA, 50(1), 55-63. 